\title{
FOS-ANKH and FOS-RUNX2 Fusion Genes in Osteoblastoma
}

\author{
IOANNIS PANAGOPOULOS ${ }^{1}$, LUDMILA GORUNOVA ${ }^{1}$, INGVILD LOBMAIER ${ }^{2}$, KRISTIN ANDERSEN ${ }^{1}$, \\ ILYÁ KOSTOLOMOV ${ }^{3}$, MARIUS LUND-IVERSEN ${ }^{2}$, BODIL BJERKEHAGEN $^{2,4,5}$ and SVERRE HEIM ${ }^{1,4}$ \\ ${ }^{1}$ Section for Cancer Cytogenetics, Institute for Cancer Genetics and Informatics, \\ The Norwegian Radium Hospital, Oslo University Hospital, Oslo, Norway; \\ ${ }^{2}$ Department of Pathology, Oslo University Hospital, Oslo, Norway; \\ ${ }^{3}$ Section for Applied Informatics, Institute for Cancer Genetics and Informatics, \\ The Norwegian Radium Hospital, Oslo University Hospital, Oslo, Norway; \\ ${ }^{4}$ Institute of Clinical Medicine, Faculty of Medicine, University of Oslo, Oslo, Norway; \\ ${ }^{5}$ Institute of Oral Biology, Faculty of Dentistry, University of Oslo, Oslo, Norway
}

\begin{abstract}
Background/Aim: Osteoblastoma is a rare benign tumor of the bones in which recurrent rearrangements of FOS have been found. Our aim was to investigate two osteoblastomas for possible genetic aberrations. Materials and Methods: Cytogenetic, RNA sequencing, and molecular analyses were performed. Results: A FOS-ANKH transcript was found in the first tumor, whereas a FOS-RUNX2 was detected in the second. Exon 4 of FOS fused with sequences either from intron 1 of ANKH or intron 5 of RUNX2. The fusion events introduced a stop codon and removed sequences involved in the regulation of FOS. Conclusion: Rearrangements and fusions of FOS show similarities with those of HMGA2 (a feature of leiomyomas and lipomas) and CSF1 (tenosynovial giant cell tumors). The replacement of a 3'-untranslated region, controlling the gene's expression, by a new sequence is thus a common pathogenetic theme shared by FOS, HMGA2, and CSF1 in many benign connective tissue tumors.
\end{abstract}

Osteoblastoma is a rare benign tumor that accounts for $1 \%$ of all bone tumors. It is most often found in patients between 10 and 30 years of age and is 2.5 more common in males than females (1). The tumor was first described in 1956 in two different publications, one by Jaffe and the other by

This article is freely accessible online.

Correspondence to: Ioannis Panagopoulos, Section for Cancer Cytogenetics, Institute for Cancer Genetics and Informatics, The Norwegian Radium Hospital, Oslo University Hospital, Montebello, PO Box 4954 Nydalen, NO-0424 Oslo, Norway. Tel: +47 22782362, e-mail: ioannis.panagopoulos@rr-research.no

Key Words: Osteoblastoma, FOS, fusion gene, FOS-ANKH, FOS$R U N X 2$, cytogenetics, RNA sequencing.
Lichtenstein $(2,3)$. In the 1970s, a more aggressive type of osteoblastoma was described under various names such as malignant osteoblastoma (4), aggressive osteoblastoma (5), and epithelioid osteoblastoma $(6,7)$. Recently, recurrent rearrangements of Fos proto-oncogene, AP-1 transcription factor subunit (FOS) and FosB proto-oncogene, AP-1 transcription factor subunit $(F O S B)$ were described in osteoblastoma and the FOS-ANKH, FOS-KIAA1199, FOS$M Y O 1 B$, FOS-IGR (in two tumors), and PPPIR10-FOSB fusion genes were found in six tumors (8).

In a previous study using RNA sequencing and other molecular genetic techniques, we found fusion of the collagen type I alpha 1 (COL1Al) and the FYN protooncogene, Src family tyrosine kinase $(F Y N)$ genes in an epithelioid osteoblastoma (9). Herein, we used cytogenetic, RNA sequencing, and other molecular genetic techniques to find a novel fusion of FOS with RUNX family transcription factor 2 ( $R U N X 2$ in chromosome band 6p21.1) in one tumor and fusion of FOS with ANKH inorganic pyrophosphate transport regulator $(A N K H$ in chromosome band $5 \mathrm{p} 15.2)$ in another osteoblastoma, proving that the FOS-ANKH fusion is recurrent in this tumor type.

\section{Materials and Methods}

Ethics statement. The study was approved by the Regional Committee for Medical and Health Research Ethics, South-East Norway (REK Sør-Øst; http://helseforskning.etikkom.no) and written informed consent was obtained from the patients' parents to publication of the case details. The ethics committee's approval included a review of the consent procedure. All patient information has been de-identified.

Case description

Case 1. The patient was a 7-year-old boy who had ongoing pain in his knee, worsening during the night. Curettage was performed. 
Case 2. The patient was an 11-year-old boy who has suffered from localized pain in his arm, worsening during the night and by frequent use. Clinically and radiologically the findings suggested osteoblastoma. The patient was operated on, with curettage, but histologically there was no tumor tissue. Radiofrequency ablation was tried 3 times, with only a short clinical effect. Open curettage was performed 2 years after first biopsy.

$G$-banding and karyotyping. Fresh tissue from a representative area of the tumors was short-term cultured and analyzed cytogenetically as previously described (10).

Fluorescence in situ hybridization (FISH). The BAC probes reported by Fitall et al. (8) were purchased from BACPAC Resource Center located at the Children's Hospital Oakland Research Institute (Oakland, CA) (https://bacpacresources.org/) (Table I). FISH analyses were performed on metaphases and interphase nuclei using a FOS (see below) home-made break-apart probe (Table I). Detailed information on the FISH procedure is given elsewhere (10).

RNA sequencing and reverse transcription (RT) PCR analyses. Total RNA was extracted from frozen $\left(-80^{\circ} \mathrm{C}\right)$ tumor tissue adjacent to that used for cytogenetic analysis and histologic examination using miRNeasy Mini Kit (Qiagen Nordic, Oslo, Norway) and 300 ng of total RNA was sent to the Genomics Core Facility at the Norwegian Radium Hospital, Oslo University Hospital (http://genomics.no/oslo/) for highthroughput paired-end RNA-sequencing. The deFuse software was used to find possible FOS fusion transcripts (11).

In order to confirm the existence of the FOS-ANKH and FOS$R U N X 2$ fusion transcripts (see below), reverse transcription (RT) PCR and Sanger sequencing analyses were performed, as described previously (10). For the detection of FOS-ANKH fusion transcript, the primer combinations were the forward FOS-F1 together with the reverse ANKH-R1 and FOS-F2 together with the reverse ANKHR2 (Table II). For the detection of FOS-RUNX2 fusion transcript, the primer combinations were the forward FOS-F3 together with the reverse RUNX-R1 and FOS-F4 together with the reverse RUNXR2 (Table II). Cycling was performed at $94^{\circ} \mathrm{C}$ for $30 \mathrm{sec}$ followed by 35 cycles of $7 \mathrm{sec}$ at $98^{\circ} \mathrm{C}, 30 \mathrm{sec}$ at $60^{\circ} \mathrm{C}, 30 \mathrm{sec}$ at $72^{\circ} \mathrm{C}$, and a final extension for $5 \mathrm{~min}$ at $72^{\circ} \mathrm{C}$. The BLAST software (http://blast.ncbi.nlm.nih.gov/Blast.cgi) was used for computer analysis of sequence data.

\section{Results}

Case 1. The G-banding analysis of short-term cultured tumor cells revealed the karyotype 46,XY,der(13;14)(q10;q10)c [6]/46,Y,der(X)t(X;3)(p22;p14 21), der(3)t(3;14)(p14 21; 23 2 4), $\operatorname{add}(5)(\mathrm{p} 15), \operatorname{der}(13 ; 14) \operatorname{ct}(\mathrm{X} ; 14)(\mathrm{p} 22 ; \mathrm{q} 23 \sim 24), \operatorname{add}(22)(\mathrm{q} 12 \sim 13$ )[9] (Figure 1A). No material was available to perform FISH analysis, nor did we have a blood sample for verification that the Robertsonian 13;14-translocation was indeed constitutional.

Using the deFuse software on the fastq files of the RNA sequencing data, a $F O S$-ANKH fusion transcript was found (Figure 1B).

RT-PCR with the primer combinations FOS-F1/ANKH-R1 and FOS-F2/ANKH-R2 amplified a 296 bp fragment and a $168 \mathrm{bp}$ fragment, respectively (data not shown). Direct sequencing of the PCR fragments showed that they were FOS-ANKH chimeric cDNA fragments (Figure 1C). There was a two nucleotides discrepancy at the fusion point between Sanger sequencing and that found by analysis of the RNA sequencing data using deFuse (Figure 1C). However, the discrepancy would not affect the ensuing output which is a TAG stop codon 6 nucleotides after the fusion point (Figures $1 \mathrm{~B}$ and 1C). Thus, in the FOS-ANKH chimeric transcript, exon 4 of FOS (nt 1061 in reference sequence with accession number NM_005252.3) was fused with a sequence from intron 1 of $A N K H$. The FOS-ANKH transcript codes for a putative protein which contains amino acid residues 1-285 of the FOS protein (accession number NP_005243.1) followed by two amino acid residues from the intronic sequence of $A N K H$.

Case 2. The karyotype was normal 46,XY in 25 examined metaphase plates (data not shown). In FISH experiments, however, the FOS probe was found to be split in both metaphase spreads examined and in 6 out of 100 interphase nuclei (Figure 2A and B). Using the deFuse software on the fastq files of the RNA sequencing data, a FUS-RUNX2 fusion transcript was found (Figure 2C).

RT-PCR with the primer combinations FOS-F3/RUNX2R1 and FOS-F4/RUNX2-R2 amplified a 509 bp fragment and a $321 \mathrm{bp}$ fragment, respectively (data not shown). Direct sequencing of the PCR fragments showed that they were FOS-RUNX2 chimeric cDNA fragments with a fusion point identical to that found by analysis of the RNA sequencing data using deFuse (Figure 2D). Thus, in the FOS-RUNX2 chimeric transcript, exon 4 of FOS (nt 945 in reference sequence with accession number NM_005252.3) was fused with a sequence from intron 5 of $R U N X 2$. The FOS-RUNX2 transcript codes for a putative protein which contains amino acid residues 1-247 of the FOS protein (accession number NP_005243.1) and 10 amino acid residues (VQRSHTTNDC) from the intronic sequence of $R U N X 2$.

\section{Discussion}

We identified FOS-ANKH and FUS-RUNX2 fusion genes in two osteoblastomas. The $F O S-A N K H$ was previously reported in another osteoblastoma (8) but, to the best of our knowledge, not in other tumors. Thus, our data showed that FOS-ANKH is a recurrent fusion gene in osteoblastomas. In both cases, the one described here and the previously reported one, part of exon 4 of FOS (nt 1061 and 982, respectively) was fused with a sequence from intron 1 of $A N K H$.

The FOS-RUNX2 fusion gene is reported here for the first time. Again, part of exon 4 of FOS was fused with an intronic sequence from the partner gene, in this case $R U N X 2$.

The FOS gene is a part of the FOS family of transcription factors which consists of 4 members: FOS (on chromosome 
Table I. BAC probes used for FISH experiments.

\begin{tabular}{lcccc}
\hline BAC clones & Chromosome band & Targeted gene & Position on GRCh38/hg38 assembly & Labelling \\
\hline RP11-484J14 & 14 q24.3 & Centromeric-FOS & chr14:75060453-75231755 & Green \\
RP11-652M15 & 14 q24.3 & Centromeric-FOS & chr14:74841928-75034860 & Green \\
RP11-905L16 & 14 q24.3 & Centromeric-FOS & chr14:74617042-74814819 & Green \\
RP11-782G23 & 14 q24.3 & Telomeric-FOS & chr14:75344174-75519840 & Red \\
RP11-714F24 & 14 q24.3 & Telomeric-FOS & chr14:75541885-75739308 & Red \\
RP11-68E9 & 14 q24.3 & Telomeric-FOS & chr14:75778914-75940947 & Red \\
\hline
\end{tabular}

Table II. Primers used for PCR amplification and Sanger sequencing analyses.

\begin{tabular}{lcccc}
\hline Name & \multicolumn{1}{c}{ Sequence $\left(5^{\prime}->3^{\prime}\right)$} & Position & Reference number & Chromosome band \\
\hline FOS-F1 & GTGGAACCTGTCAAGAGCATCAG & $962-984$ & NM_005252.3 & $14 \mathrm{q} 24.3$ \\
ANKH-R1 & ATTCATGTTGTGCTCTCAGAATGG & $14789425-14789448$ & NC_000005.10 & $5 \mathrm{p} 15.2$ \\
FOS-F2 & CTGAAGACCGAGCCCTTTGAT & $995-1015$ & NM_005252.3 & $14 \mathrm{q} 24.3$ \\
ANKH-R2 & TTCAGTGTTTGGCTTGGTAACCT & $14789520-14789542$ & NC_000005.10 & $5 \mathrm{p} 15.2$ \\
FOS-F3 & AGACCGAGATTGCCAACCTGCT & $744-765$ & NM_005252.3 & $14 \mathrm{q} 24.3$ \\
RUNX2-R1 & AGCGGCTCAAAGGGCTAGAGG & $45483160-45483180$ & NC_000006.12 & $6 \mathrm{p} 21.1$ \\
FOS-F4 & ACCTGCCTGCAAGATCCCTGAT & $808-829$ & NM_005252.3 & $14 \mathrm{q} 24.3$ \\
RUNX2-R2 & GCAGCCTTTCCCAGCAAAGATT & $45483284-45483305$ & NC_000006.12 & $6 \mathrm{p} 21.1$ \\
\hline
\end{tabular}

band 14q24.3), FOSB (on band 19q13.3), FOSL1 (on band 11q13.1), and FOSL2 (on band 2p23.2). These genes encode leucine zipper proteins that can dimerize with proteins of the JUN family, thereby forming the transcription factor complex AP-1 $(12,13)$. As such, the FOS proteins have been implicated as regulators of cell proliferation, differentiation, and transformation (12-16).

The amount of FOS protein in cells is tightly regulated at the transcriptional and translational levels and by interaction between transcription and translation (17-20). In the 3'untranslated region (3'-UTR), there are two domains of AUrich elements involved in the stability of FOS mRNA, a localization signal which binds the mRNA to the perinuclear cytoskeleton, a sequence that binds the miR-7b miRNA decreasing mRNA translation, and AU-rich regions which interact with parts of FOS coding regions facilitating mRNA deadenylation (poly(A) tail-shortening process) and decay by a mechanism coupled to translation $(17,19,21-27)$. FOS is an unstable, easily degradable protein. The carboxy terminal part of FOS was found to be essential for FOS protein degradation $(18,20,28-32)$.

Rearrangements and fusions of $F O S$ have been reported in epithelioid hemangioma of the bone (FOS-LMNA, FOS$M B N L 1$, and FOS-VIM) as well as in osteoblastoma (FOSRUNX2, FOS-ANKH, FOS-CEMIP, and FOS-MYOIB) (8, $33,34)$. In all examined cases, the breakpoint occurred in exon 4 where the fusion event introduced a stop codon and removed both the C-terminal part of FOS, which is essential for FOS degradation, and the 3'- untranslated region of FOS mRNA which maintains $F O S$ mRNA stability $(8,33,34)$.

The resulting, truncated FOS protein contains the Nterminal transactivation domain, which plays a crucial role in transformation, and the basic leucine zipper domain (bZIP) making it more stable than wild-type FOS (8, 20, 33$35)$. In vitro experiments have shown that truncated FOS protein is resistant to degradation and has a longer half-life than the wild-type FOS protein (circa 1-2 h) (20).

Rearrangements of FOS and its fusion with various partners share similarities with rearrangements and fusions of the HMGA2 and CSF1 genes. In lipomas and other benign connective tissue tumors, chromosome aberrations, mainly translocations, disrupt the HMGA2 locus in $12 \mathrm{q} 14$ and fuse part of $H M G A 2$ with various partners (10, 36-42). In all reported cases, the pattern is the same: Disruption of the HMGA2 locus leaves intact exons 1-3 which encode the AThook domains separating them from the 3'-untranslated region of the gene (3'-UTR). The 3'-UTR of HMGA2 was shown to regulate transcription of the HMGA2 gene (43-45). Mouse embryonic NIH3T3 fibroblasts are transformed in vitro by the expression of truncated HMGA2 protein carrying the three DNA-binding domains (46). Overexpression of truncated HMGA2 in human myometrial cells was shown to induce leiomyoma-like lesions (47). Moreover, transgenic mice expressing a truncated form of the HMGA2 protein developed benign mesenchymal tumors $(48,49)$. 


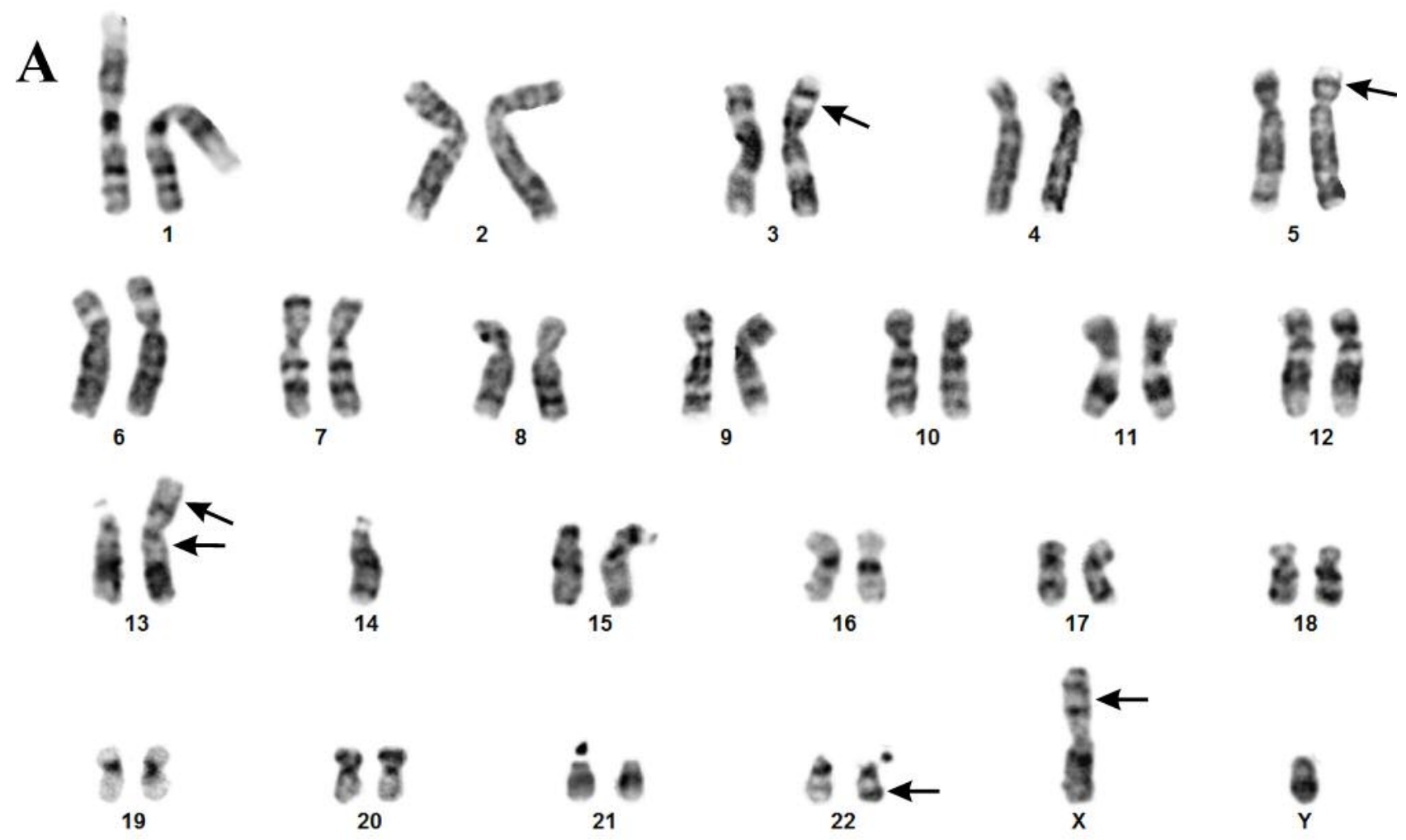

B

GAAAGGAATAAGATGGCTGCAGCCAAATGCCGCAACCGGAGGAGGGAGCTGACTGATACACT CCAAGCGGAGACAGACCAACTAGAAGATGAGAAGTCTGCTTTGCAGACCGAGATTGCCAACC TGCTGAAGGAGAAGGAAAAACTAGAGTTCATCCTGGCAGCTCACCGACСTGCCTGCAAGATC ССTGATGACCTGGGCTTCCCAGAAGAGATGTCTGTGGCTTCCСTTGATCTGACTGGGGGCCT GCCAGAGGTTGCCACCCCGGAGTCTGAGGAGGCCTTCACCСTGCCTCTCCTCAATGACCCTG AGCCCAAGCCCTCAGTGGAACCTGTCAAGAGCATCAGCAGCATGGAGCTGAAGACCGAGCCC TTTGATGACTTCCTGTTCCCAGCATCATCCAGGCCCAGTGGCTCTGAGACAG|AATTT|TAGG AGATTCCСTTTTATTCTCAATAAAATAGAAAGAAATATTTACTGTGGTTTATTCCTTAGTGT TAAAGAGAGGTTACCAAGCCAAACACTGAATACTTTAGAAAATTTCTAGATAGACACAGCTT AGAAATGGAGCTTAGCTTTTTTTTTTTTTTTTATCACCACCATTCTGAGAGCACAACATGAA TTTAGGATAGTTGAATGGGACCTAAATGTGATGCAAGGATATTAAATTTGCTTTTAAAAAAT GCATTTAACTCATACGGAAG

C FOS exon $4 \downarrow$ \NKH intron 1

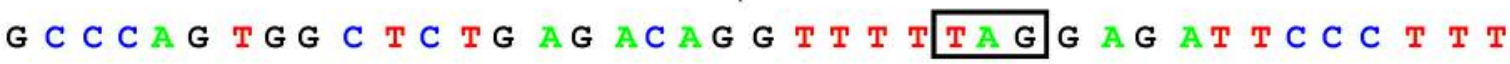

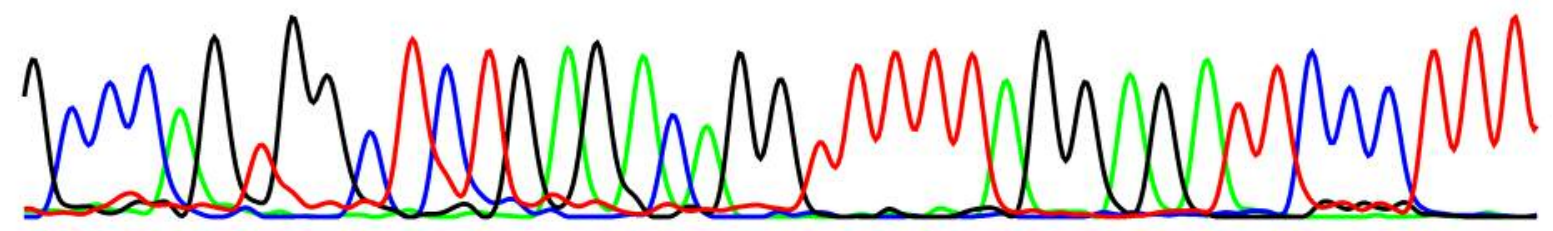

Figure 1. Genetic analyses of the osteoblastoma of case 1. (A) Karyogram showing the chromosome aberrations (arrows). (B) FOS-ANKH fusion sequence obtained from the raw data using deFuse software after RNA sequencing. The GIA junction of FOS with ANKH is highlighted in red. The position of the forward FOS-F1 and reverse ANKH-R1 primers are highlighted in green. The position of the forward FOS-F2 and the reverse ANKH$R 2$ primers are highlighted in blue. (C) Partial sequence chromatogram of the cDNA amplified fragment showing the junction position of FOS with intron 1 of ANKH. 

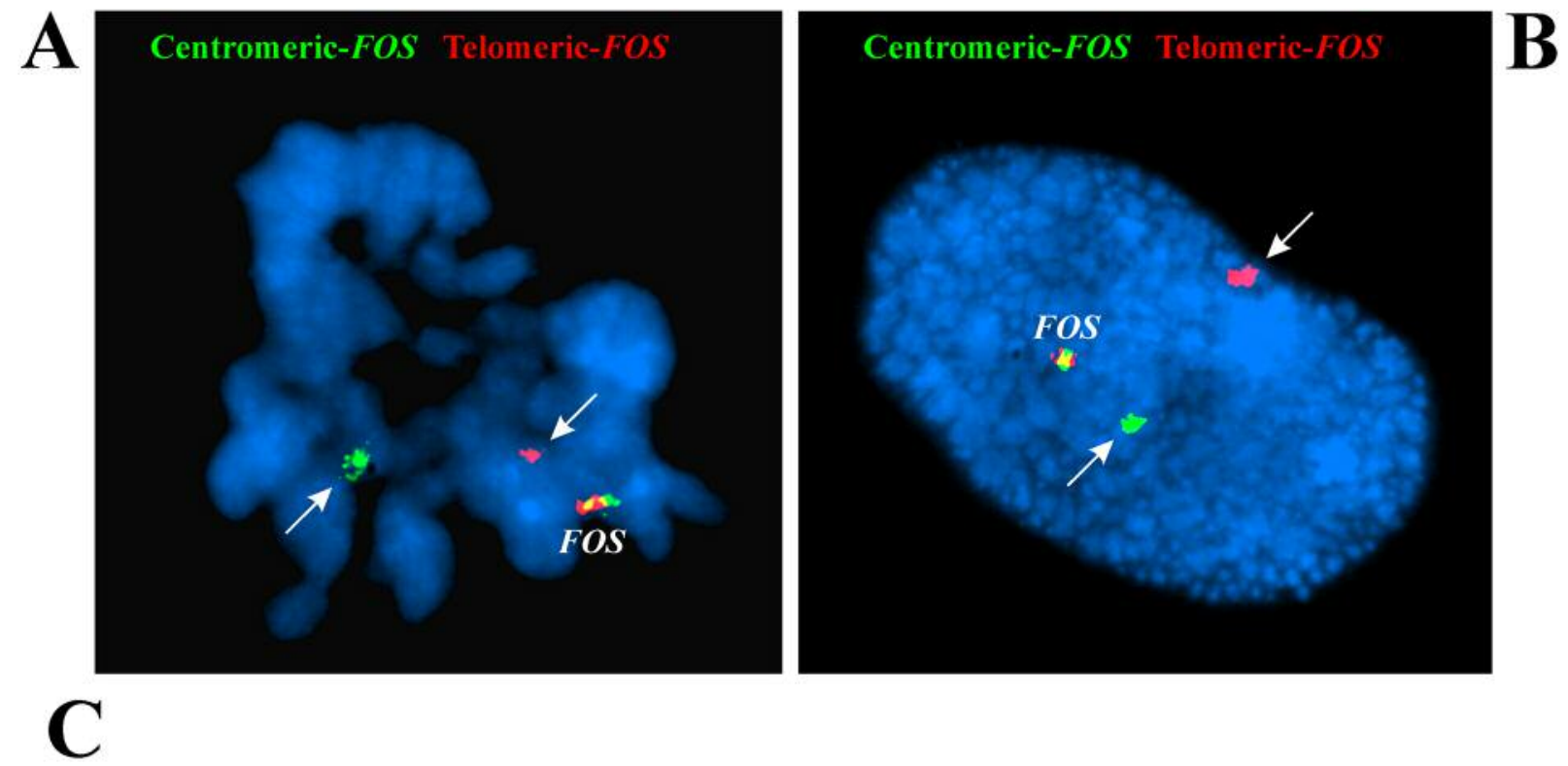

CCAGGGCTGGCGTTGTGAAGACCATGACAGGAGGCCGAGCGCAGAGCATTGGCAGGAGGGGC AAGGTGGAACAGTTATCTCCAGAAGAAGAAGAGAAAAGGAGAATCCGAAGGGAAAGGAATAA GATGGCTGCAGCCAAATGCCGCAACCGGAGGAGGGAGCTGACTGATACACTCCAAGCGGAGA CAGACCAACTAGAAGATGAGAAGTCTGCTTTGCAGACCGAGATTGCCAACCTGCTGAAGGAG AAGGAAAAACTAGAGTTCATCCTGGCAGCTCACCGACCTGCCTGCAAGATCCCTGATGACCT GGGCTTCCCAGAAGAGATGTCTGTGGCTTCCСTTGATCTGACTGGGGGCCTGCCAGAGGTTG CCACCCCGGATCTGAGGAGGCСTTCACССTGCСTCTCCTCAATGACCC| GGTACAGAGAAG TCACACAACAAATGATTGCTGA TTAAAAAATAAGAACATGGATAAATTTAAAATTATCTGT ACTTTTGTCCAGTAAAGACAAAGAAGACAGAAAAAAAAAAAGCTGGTTATTGGGAAACATTT CCСACAGTAAAATTGATGAGTCTATAATСTTTGCTGGGAAAGGCTGCTGCGTСATСTTTTTC ССTAAGAGTGCACTGTCTGATTCAGGTCAGAAACTATTTCTGGACTAGAATAATGAAATGGG CTAAGAAACTGTCTTCATGTTTAAGGCCTCTAGCCCTTTGAGCCGCTGGA

\section{FOS exon $4 \downarrow R U N X 2$ intron 5}

C TG C T T T C T CAA T G AC C CG T ACA GAG AAGTCACACAA

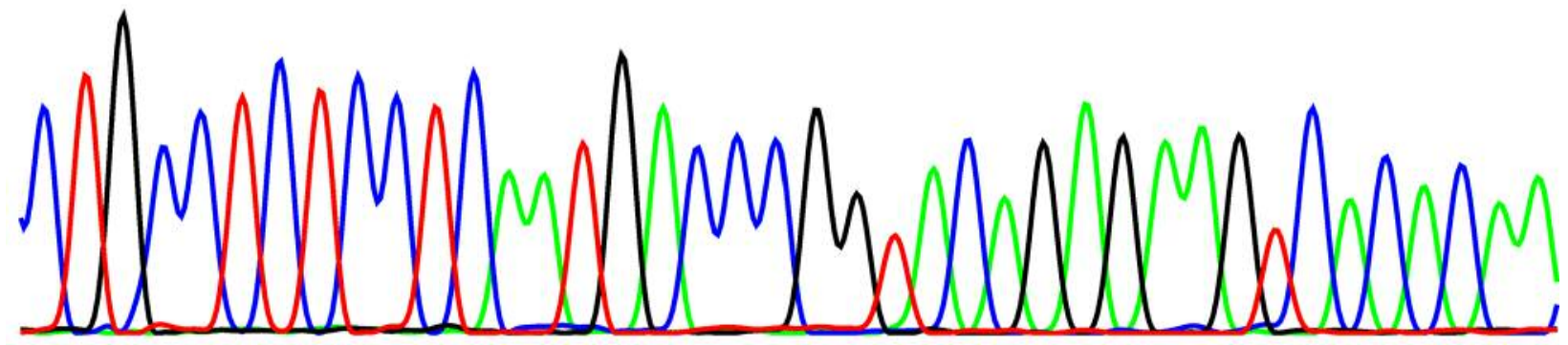

Figure 2. Genetic analyses of the osteoblastoma of case 2. (A) Fluorescence in situ hybridization (FISH) on a metaphase plate with the FOS breakapart probe. (B) FISH on interphase nucleus with the FOS break-apart probe. (C) FOS-RUNX2 fusion sequence obtained from the raw data after RNA sequencing using the deFuse software package. The ClG junction of FOS with RUNX2 is highlighted in red. The position of the forward FOS$F 3$ and reverse RUNX2-R1 primers are highlighted in green. The position of the forward FOS-F4 and the reverse RUNX-R2 primers are highlighted in blue. (C) Partial sequence chromatogram of the cDNA amplified fragment showing the junction position of FOS with intron 5 of RUNX2. 
In tenosynovial giant cell tumors, chromosome aberrations, mainly translocations, disrupt the CSF1 locus in $1 \mathrm{p} 13$ and replace the 3'-UTR of CSF1 (exon 9 in sequence with accession number NM_000757) with new sequences contributed by the rearrangement partner (50-52). Exon 9 of CSF1 mRNA (accession number NM-000575) contains microRNA targets (miRNA), a noncanonical G-quadruplex, and AU-rich elements (AREs) which control CSF1 expression (53-56)

Thus, replacement of the expression-controling 3'-UTR region with a new sequence, often contributed by a translocation partner, appears to be a common pathogenetic theme shared by FOS, HMGA2, and CSF 1 and occurring particularly often in benign connective tissue tumors.

\section{Conflicts of Interest}

The Authors declare that they have no potential conflicts of interest in regard to this study.

\section{Authors' Contributions}

IP designed and supervised the research, performed molecular genetic experiments, bioinformatics analysis, and wrote the article. LG performed cytogenetic analysis and evaluated the FISH data. IL performed pathological examination. KA performed molecular genetic experiments, FISH analyses, and evaluated the data. IK performed the bioinformatic analyses. ML-I performed pathological examination. BB performed pathological examination. SH assisted with experimental design and writing of the article. All Authors read and approved of the final manuscript.

\section{Acknowledgements}

This work was supported by grants from Radiumhospitalets Legater.

\section{References}

1 de Andrea CE, A. BJ and Schiller A: Osteoblastoma. In: World Health Organization Classification of Tumours. Pathology and Genetics of Tumours of Soft Tissue and Bone (Fletcher CDM, Bridge JA, Hogendoorn PCW, Mertens F eds.). Lyon: IARC Press, pp. 279-280, 2013.

2 Jaffe HL: Benign osteoblastoma. Bull Hosp Joint Dis 17(2): 141151, 1956. PMID: 13413389.

3 Lichtenstein L: Benign osteoblastoma; a category of osteoid-and bone-forming tumors other than classical osteoid osteoma, which may be mistaken for giant-cell tumor or osteogenic sarcoma. Cancer 9(5): 1044-1052, 1956. PMID: 13364889. DOI: 10.1002/1097-0142(195609/10)9:5<1044::aid-cncr28200 90523>3.0.co;2-o

4 Schajowicz F and Lemos C: Malignant osteoblastoma. J Bone Joint Surg Br 58(2): 202-211, 1976. PMID: 932083.

5 Revell PA and Scholtz CL: Aggressive osteoblastoma. J Pathol 127(4): 195-198, 1979. PMID: 469645. DOI: 10.1002/path. 1711270406

6 Deyrup AT and Montag AG: Epithelioid and epithelial neoplasms of bone. Arch Pathol Lab Med 131(2): 205-216, 2007. PMID:
17284104. DOI: 10.1043/1543-2165(2007)131[205:EAENOB] 2.0.CO;2

7 Britt JD, Murphey MD and Castle JT: Epithelioid osteoblastoma. Head Neck Pathol 6(4): 451-454, 2012. PMID: 22528828. DOI: 10.1007/s12105-012-0356-5

8 Fittall MW, Mifsud W, Pillay N, Ye H, Strobl AC, Verfaillie A, Demeulemeester J, Zhang L, Berisha F, Tarabichi M, Young MD, Miranda E, Tarpey PS, Tirabosco R, Amary F, Grigoriadis AE, Stratton MR, Van Loo P, Antonescu CR, Campbell PJ, Flanagan AM and Behjati S: Recurrent rearrangements of FOS and FOSB define osteoblastoma. Nat Commun 9(1): 2150, 2018. PMID: 29858576. DOI: 10.1038/s41467-018-04530-Z

9 Panagopoulos I, Gorunova L, Lobmaier I, Lund-Iversen M, Andersen K, Holth A, Bjerkehagen B and Heim S: Fusion of the COL1A1 and FYN Genes in Epithelioid Osteoblastoma. Cancer Genomics Proteomics 16(5): 361-368, 2019. PMID: 31467230. DOI: $10.21873 / \operatorname{cgp} .20141$

10 Panagopoulos I, Bjerkehagen B, Gorunova L, Taksdal I and Heim S: Rearrangement of chromosome bands 12q14 15 causing HMGA2-SOX5 gene fusion and HMGA2 expression in extraskeletal osteochondroma. Oncol Rep 34(2): 577-584, 2015. PMID: 26043835. DOI: 10.3892/or.2015.4035

11 McPherson A, Hormozdiari F, Zayed A, Giuliany R, Ha G, Sun MG, Griffith M, Heravi Moussavi A, Senz J, Melnyk N, Pacheco M, Marra MA, Hirst M, Nielsen TO, Sahinalp SC, Huntsman D and Shah SP: deFuse: an algorithm for gene fusion discovery in tumor RNA-Seq data. PLoS Comput Biol 7(5): e1001138, 2011. PMID: 21625565. DOI: 10.1371/journal.pcbi.1001138

12 Hess J, Angel P and Schorpp-Kistner M: AP-1 subunits: quarrel and harmony among siblings. J Cell Sci 117(Pt 25): 5965-5973, 2004. PMID: 15564374. DOI: 10.1242/jcs.01589

13 Bejjani F, Evanno E, Zibara K, Piechaczyk M and Jariel-Encontre I: The AP-1 transcriptional complex: Local switch or remote command? Biochim Biophys Acta Rev Cancer 1872(1): 11-23, 2019. PMID: 31034924. DOI: 10.1016/j.bbcan.2019.04.003

14 Tulchinsky E: Fos family members: regulation, structure and role in oncogenic transformation. Histol Histopathol 15(3): 921928, 2000. PMID: 10963134. DOI: 10.14670/HH-15.921

15 Milde-Langosch K: The Fos family of transcription factors and their role in tumourigenesis. Eur J Cancer 41(16): 2449-2461, 2005. PMID: 16199154. DOI: 10.1016/j.ejca.2005.08.008

16 Alfonso-Gonzalez C and Riesgo-Escovar JR: Fos metamorphoses: Lessons from mutants in model organisms. Mech Dev 154: 73-81, 2018. PMID: 29753813. DOI: 10.1016/j.mod.2018.05.006

17 Chen CY, Chen TM and Shyu AB: Interplay of two functionally and structurally distinct domains of the c-fos AU-rich element specifies its mRNA-destabilizing function. Mol Cell Biol 14(1): 416-426, 1994. PMID: 7903419. DOI: $10.1128 / \mathrm{mcb} .14 .1 .416$

18 Ferrara P, Andermarcher E, Bossis G, Acquaviva C, Brockly F, Jariel-Encontre I and Piechaczyk M: The structural determinants responsible for c-Fos protein proteasomal degradation differ according to the conditions of expression. Oncogene 22(10): 14611474, 2003. PMID: 12629509. DOI: 10.1038/sj.onc.1206266

19 Grosset C, Chen CY, Xu N, Sonenberg N, Jacquemin-Sablon H and Shyu AB: A mechanism for translationally coupled mRNA turnover: interaction between the poly(A) tail and a c-fos RNA coding determinant via a protein complex. Cell 103(1): 29-40, 2000. PMID: 11051545. DOI: 10.1016/s0092-8674(00)00102-1

20 van IDGP, Forghany Z, Liebelt F, Vertegaal AC, Jochemsen AG, Bovee J, Szuhai K and Baker DA: Functional analyses of a human 
vascular tumor FOS variant identify a novel degradation mechanism and a link to tumorigenesis. J Biol Chem 292(52): 21282-21290, 2017. PMID: 29150442. DOI: $10.1074 /$ jbc.C117.815845

21 Chen CY, You Y and Shyu AB: Two cellular proteins bind specifically to a purine-rich sequence necessary for the destabilization function of a c-fos protein-coding region determinant of mRNA instability. Mol Cell Biol 12(12): 57485757, 1992. PMID: 1448102. DOI: $10.1128 / \mathrm{mcb} .12 .12 .5748$

22 Chen $\mathrm{CY}, \mathrm{Xu} \mathrm{N}$ and Shyu AB: mRNA decay mediated by two distinct AU-rich elements from c-fos and granulocytemacrophage colony-stimulating factor transcripts: different deadenylation kinetics and uncoupling from translation. Mol Cell Biol 15(10): 5777-5788, 1995. PMID: 7565731. DOI: $10.1128 / \mathrm{mcb} .15 .10 .5777$

23 Dalgleish G, Veyrune JL, Blanchard JM and Hesketh J: mRNA localization by a 145-nucleotide region of the c-fos 3'untranslated region. Links to translation but not stability. J Biol Chem 276(17): 13593-13599, 2001. PMID: 11139568 DOI: 10.1074/jbc.M001141200

24 Lee HJ, Palkovits M and Young WS, 3rd: miR-7b, a microRNA up-regulated in the hypothalamus after chronic hyperosmolar stimulation, inhibits Fos translation. Proc Natl Acad Sci U S A 103(42): 15669-15674, 2006. PMID: 17028171. DOI: 10.1073/pnas.0605781103

25 Schiavi SC, Wellington CL, Shyu AB, Chen CY, Greenberg ME and Belasco JG: Multiple elements in the c-fos protein-coding region facilitate mRNA deadenylation and decay by a mechanism coupled to translation. J Biol Chem 269(5): 34413448, 1994. PMID: 8106384.

26 Shyu AB, Belasco JG and Greenberg ME: Two distinct destabilizing elements in the $\mathrm{c}$-fos message trigger deadenylation as a first step in rapid mRNA decay. Genes Dev 5(2): 221-231, 1991. PMID: 1899842. DOI: 10.1101/gad.5.2.221

27 Shyu AB, Greenberg ME and Belasco JG: The c-fos transcript is targeted for rapid decay by two distinct mRNA degradation pathways. Genes Dev 3(1): 60-72, 1989. PMID: 2496006. DOI: 10.1101/gad.3.1.60

28 Acquaviva C, Brockly F, Ferrara P, Bossis G, Salvat C, JarielEncontre I and Piechaczyk M: Identification of a C-terminal tripeptide motif involved in the control of rapid proteasomal degradation of c-Fos proto-oncoprotein during the $\mathrm{G}(0)$-to-S phase transition. Oncogene 20(51): 7563-7572, 2001. PMID: 11709728. DOI: $10.1038 /$ sj.onc. 1204880

29 Tsurumi C, Ishida N, Tamura T, Kakizuka A, Nishida E, Okumura E, Kishimoto T, Inagaki M, Okazaki K and Sagata N: Degradation of c-Fos by the $26 \mathrm{~S}$ proteasome is accelerated by c-Jun and multiple protein kinases. Mol Cell Biol 15(10): 56825687, 1995. PMID: 7565719. DOI: 10.1128/mcb.15.10.5682

30 Adler J, Reuven N, Kahana C and Shaul Y: c-Fos proteasomal degradation is activated by a default mechanism, and its regulation by $\mathrm{NAD}(\mathrm{P}) \mathrm{H}$ :quinone oxidoreductase 1 determines cFos serum response kinetics. Mol Cell Biol 30(15): 3767-3778, 2010. PMID: 20498278. DOI: 10.1128/MCB.00899-09

31 Bossis G, Ferrara P, Acquaviva C, Jariel-Encontre I and Piechaczyk M: c-Fos proto-oncoprotein is degraded by the proteasome independently of its own ubiquitinylation in vivo. Mol Cell Biol 23(20): 7425-7436, 2003. PMID: 14517309. DOI: 10.1128/mcb.23.20.7425-7436.2003

32 Campbell KM, Terrell AR, Laybourn PJ and Lumb KJ: Intrinsic structural disorder of the $\mathrm{C}$-terminal activation domain from the
bZIP transcription factor Fos. Biochemistry 39(10): 2708-2713, 2000. PMID: 10704222. DOI: 10.1021/bi9923555

33 Huang SC, Zhang L, Sung YS, Chen CL, Krausz T, Dickson BC, Kao YC, Agaram NP, Fletcher CD and Antonescu CR: Frequent FOS Gene Rearrangements in Epithelioid Hemangioma: A Molecular Study of 58 Cases With Morphologic Reappraisal. Am J Surg Pathol 39(10): 1313-1321, 2015. PMID: 26135557. DOI: $10.1097 /$ PAS.0000000000000469

34 van IDG, de Jong D, Romagosa C, Picci P, Benassi MS, Gambarotti M, Daugaard S, van de Sande M, Szuhai K and Bovee JV: Fusion events lead to truncation of FOS in epithelioid hemangioma of bone. Genes Chromosomes Cancer 54(9): 565574, 2015. PMID: 26173738. DOI: 10.1002/gcc.22269

35 Jooss KU, Funk M and Muller R: An autonomous N-terminal transactivation domain in Fos protein plays a crucial role in transformation. EMBO J 13(6): 1467-1475, 1994. PMID: 8137828.

36 Schoenmakers EF, Wanschura S, Mols R, Bullerdiek J, Van den Berghe $\mathrm{H}$ and Van de Ven WJ: Recurrent rearrangements in the high mobility group protein gene, $H M G I-C$, in benign mesenchymal tumours. Nat Genet 10(4): 436-444, 1995. PMID: 7670494. DOI: $10.1038 / n g 0895-436$

37 Agostini A, Gorunova L, Bjerkehagen B, Lobmaier I, Heim S and Panagopoulos I: Molecular characterization of the $\mathrm{t}(4 ; 12)(\mathrm{q} 27 \sim 28 ; \mathrm{q} 14 \sim 15)$ chromosomal rearrangement in lipoma. Oncol Lett 12(3): 1701-1704, 2016. PMID: 27588119. DOI: 10.3892/ol.2016.4834

38 Broberg K, Zhang M, Strömbeck B, Isaksson M, Nilsson M, Mertens F, Mandahl N and Panagopoulos I: Fusion of RDC1 with $H M G A 2$ in lipomas as the result of chromosome aberrations involving 2q35-37 and 12q13-15. Int J Oncol 21(2): 321-326, 2002. PMID: 12118328.

39 Cleynen I and Van de Ven WJ: The HMGA proteins: a myriad of functions (Review). Int J Oncol 32(2): 289-305, 2008. PMID: 18202751.

40 Nilsson M, Mertens F, Höglund M, Mandahl $\mathrm{N}$ and Panagopoulos I: Truncation and fusion of $H M G A 2$ in lipomas with rearrangements of $5 \mathrm{q} 32->\mathrm{q} 33$ and $12 \mathrm{q} 14->\mathrm{q} 15$. Cytogenet Genome Res 112(1-2): 60-66, 2006. PMID: 16276091. DOI: $10.1159 / 000087514$

41 Panagopoulos I, Gorunova L, Agostini A, Lobmaier I, Bjerkehagen B and Heim S: Fusion of the HMGA2 and C9orf92 genes in myolipoma with $\mathrm{t}(9 ; 12)(\mathrm{p} 22 ; \mathrm{q} 14)$. Diagn Pathol 11: 22, 2016. PMID: 26857357. DOI: 10.1186/s13000-016-0472-8

42 Panagopoulos I, Gorunova L, Andersen HK, Pedersen TD, Lømo J, Lund-Iversen M, Micci F and Heim S: Genetic Characterization of Myoid Hamartoma of the Breast. Cancer Genomics Proteomics 16(6): 563-568, 2019. PMID: 31659109. DOI: 10.21873/cgp.20158

43 Borrmann L, Wilkening S and Bullerdiek J: The expression of HMGA genes is regulated by their 3'UTR. Oncogene 20(33): 4537-4541, 2001 PMID: 11494149. DOI: 10.1038/sj.onc.1204577

44 Mayr C, Hemann MT and Bartel DP: Disrupting the pairing between let-7 and Hmga2 enhances oncogenic transformation. Science 315(5818): 1576-1579, 2007. PMID: 17322030. DOI: 10.1126/science.1137999

45 Kristjansdottir K, Fogarty EA and Grimson A: Systematic analysis of the Hmga2 3' UTR identifies many independent regulatory sequences and a novel interaction between distal sites. RNA 21(7): 1346-1360, 2015. PMID: 25999317. DOI: 10.1261/rna.051177.115 
46 Fedele M, Berlingieri MT, Scala S, Chiariotti L, Viglietto G, Rippel V, Bullerdiek J, Santoro M and Fusco A: Truncated and chimeric HMGI-C genes induce neoplastic transformation of NIH3T3 murine fibroblasts. Oncogene 17(4): 413-418, 1998. PMID: 9696033. DOI: 10.1038/sj.onc.1201952

47 Mas A, Cervello I, Fernandez-Alvarez A, Faus A, Diaz A, Burgues O, Casado $\mathrm{M}$ and Simon C: Overexpression of the truncated form of High Mobility Group A proteins (HMGA2) in human myometrial cells induces leiomyoma-like tissue formation. Mol Hum Reprod 21(4): 330-338, 2015. PMID: 25542836. DOI: $10.1093 / \mathrm{molehr} / \mathrm{gau} 114$

48 Arlotta P, Tai AK, Manfioletti G, Clifford C, Jay G and Ono SJ: Transgenic mice expressing a truncated form of the high mobility group I-C protein develop adiposity and an abnormally high prevalence of lipomas. J Biol Chem 275(19): 14394-14400, 2000. PMID: 10747931. DOI: $10.1074 /$ jbc.m000564200

49 Zaidi MR, Okada Y and Chada KK: Misexpression of full-length HMGA2 induces benign mesenchymal tumors in mice. Cancer Res 66(15): 7453-7459, 2006. PMID: 16885341. DOI: 10.1158/00085472.CAN-06-0931

50 Ho J, Peters T, Dickson BC, Swanson D, Fernandez A, FrovaSeguin A, Valentin MA, Schramm U, Sultan M, Nielsen TO and Demicco EG: Detection of CSF1 rearrangements deleting the 3' UTR in tenosynovial giant cell tumors. Genes Chromosomes Cancer 59(2): 96-105, 2020. PMID: 31469468. DOI: $10.1002 / \mathrm{gcc} .22807$

51 Panagopoulos I, Brandal P, Gorunova L, Bjerkehagen B and Heim S: Novel CSF1-S100A10 fusion gene and CSF 1 transcript identified by RNA sequencing in tenosynovial giant cell tumors. Int J Oncol 44(5): 1425-1432, 2014. PMID: 24604026. DOI: 10.3892/ijo.2014.2326

52 Tsuda Y, Hirata M, Katayama K, Motoi T, Matsubara D, Oda Y, Fujita M, Kobayashi H, Kawano H, Nishida Y, Sakai T, Okuma T, Goto T, Ogura K, Kawai A, Ae K, Anazawa U, Suehara Y, Iwata S, Miyano S, Imoto S, Shibata T, Nakagawa H, Yamaguchi R, Tanaka $\mathrm{S}$ and Matsuda K: Massively parallel sequencing of tenosynovial giant cell tumors reveals novel CSF1 fusion transcripts and novel somatic CBL mutations. Int J Cancer 145(12): 3276-3284, 2019. PMID: 31107544. DOI: 10.1002/ijc.32421
53 Bonafé N, Gilmore-Hebert M, Folk NL, Azodi M, Zhou Y and Chambers SK: Glyceraldehyde-3-phosphate dehydrogenase binds to the AU-Rich 3' untranslated region of colonystimulating factor-1 (CSF-1) messenger RNA in human ovarian cancer cells: possible role in CSF-1 posttranscriptional regulation and tumor phenotype. Cancer Res 65(9): 3762-3771, 2005. PMID: 15867372. DOI: 10.1158/0008-5472.CAN-04-3954

54 Woo HH, Baker T, Laszlo C and Chambers SK: Nucleolin mediates microRNA-directed CSF-1 mRNA deadenylation but increases translation of CSF-1 mRNA. Mol Cell Proteomics 12(6): 16611677, 2013. PMID: 23471483. DOI: 10.1074/mcp.M112.025288

55 Woo HH, Laszlo CF, Greco S and Chambers SK: Regulation of colony stimulating factor- 1 expression and ovarian cancer cell behavior in vitro by miR-128 and miR-152. Mol Cancer 11: 58, 2012. PMID: 22909061. DOI: 10.1186/1476-4598-11-58

56 Zhou Y, Yi X, Stoffer JB, Bonafé N, Gilmore-Hebert M, McAlpine $J$ and Chambers SK: The multifunctional protein glyceraldehyde-3-phosphate dehydrogenase is both regulated and controls colony-stimulating factor-1 messenger RNA stability in ovarian cancer. Mol Cancer Res 6(8): 1375-1384, 2008. PMID: 18708368. DOI: 10.1158/1541-7786.MCR-07-2170
Received December 3, 2019

Revised December 19, 2019 Accepted December 30, 2019 